\title{
EFICÁCIA E SELETIVIDADE DA MISTURA TRIFLOXYSULFURON-SODIUM/AMETRYNE PARA O CONTROLE DE PLANTAS DANINHAS NA CULTURA DA CANA-DE-AÇÚCAR
}

\author{
Antônio Carlos de Barros ${ }^{1}$ e Denilson Miranda Leonel ${ }^{2}$
}

'Eng. ${ }^{\circ}$ Agrônomo., Pequisador. AgênciaRural. Caixa Postal 211. Jataí-GO 75800-069

2Eng. ${ }^{\circ}$ Agrônomo., Supervisor de Agronomia. Usina Santa Helena de Açúcar e Álcool S/A. Caixa Postal 33. Jataí, GO 75929-000

\section{RESUMO}

Conduziu-se um ensaio na Usina Santa Helena, município de Santa Helena de Goiás-GO, no ano agrícola 1999/2000, com o objetivo de avaliar a eficácia biológica de trifloxysulfuron-sodium/ametryne para o controle das plantas daninhas, bem como avaliar a seletividade dos mesmos para a cana-de-açúcar. O delineamento adotado foi o de blocos ao acaso, com oito tratamentos e quatro repetições. Os tratamentos foram: testemunha sem capina, testemunha capinada, trifloxysulfuron-sodium/ ametryne (mistura formulada) a 32/1280, 37/1463 e 42/1646 g/ha, trifloxysulfuron-sodium+ametryne (mistura em tanque) a $37+1500 \mathrm{~g} / \mathrm{ha}$, hexazinone/diuron $(330 / 1170 \mathrm{~g} / \mathrm{ha})$ e trifloxysulfuron-sodium $(22 \mathrm{~g} / \mathrm{ha})$. Os herbicidas foram aplicados em pós-emergência, com as plantas daninhas de folhas largas com 4 a 6 folhas e as gramíneas com 2 a 3 perfilhos. Carrapichode-carneiro (Acanthospermum hispidum), apaga-fogo (Alternanthera tenella), erva-de-santa-luzia (Chamaesyce hirta) e capim-colchão (Digitaria horizontalis) foram eficientemente controlados por trifloxysulfuron-sodium/ametryne (mistura formulada) a 32/1280, 37/1463 e 42/1646 g/ha e por trifloxysulfuron-sodium+ametryne (mistura em tanque) a 37+1500 g/ha, equivalendo-se ao padrão hexazinone/diuron (330/1170 g/ha). Trifloxysulfuron-sodium isolado, a 22 g/ha, proporcionou baixo controle do capim-colchão e eficiente controle das espécies daninhas de folhas largas. Nas doses testadas os herbicidas foram seletivos para a cana-de-açúcar cv. RB 84-5257. Não se observaram diferenças significativas, entre os diversos tratamentos testados, para a altura de plantas, número de perfilhos e produção da cana-de-açúcar, embora a testemunha sem capina tenha produzido $5,4 \%$ menos do que a testemunha capinada.

Palavras-chave: diuron, hexazinone, pós-emergência, Saccharum spp.

\section{ABSTRACT \\ Efficacy and selectivity of trifloxysulfuron-sodium/ametryne in the control of weeds in sugar cane fields}

A trial was carried out in a sugar cane field in Santa Helena County, Goias State, Brazil, during the 1999/2000 growing season. The objectives were to evaluate the agronomic efficiency of a misture of trifloxysulfuron-sodium/ametryne in the control of weeds and to evaluate the selectivity for sugar cane. The experimental design was a completely randomized block with four replications and eight treatments. The treatments were as follows: cleaned and noncleaned plots, trifloxysulfuronsodium/ametryne $(32 / 1280,37 / 1463$ and $42 / 1646 \mathrm{~g} / \mathrm{ha})$, trifluxysulfuron-sodium+ametryne (tank mixture), at $37+1500 \mathrm{~g} /$ ha, hexazinone/diuron (330/1170 g/ha) and trifluxysulfuron-sodium (22 g/ha). The herbicides were applied at postemergence, with the broadleaf weeds at the 4 to 6 leaf stage and the grasses at 2 to 3 stem stage. Acanthospermum hispidum, Alternanthera tenella, Chamaesyce hirta and Digitaria horizontalis were effectively controlled with trifloxysulfuron-sodium/ametryne at 
all studied rates, trifloxyxulfuron-sodium+ametryne (tank mixture) at 37+1500 g/ha, and hexazinone/diuron (330/1170 g/ ha). Trifloxysulfuron-sodium ( $22 \mathrm{~g} / \mathrm{ha}$ ) showed very low control of Digitaria horizontalis as well as an efficient control of broadleaf weeds. All herbicide doses were selective for sugar cane cv. RB 84-5257. There were no statistical differences for sugar cane plant height, new stem formation and yield, although the control, where weeds were not cut, presented a 5,4\% reduction in yield compared to the control where it was not cleaned.

Key words: diuron, hexazinone, postemergence, Saccharum spp.

\section{INTRODUÇÃO}

A cana-de-açúcar é uma das culturas de maior importância sócio-econômica para o Brasil. No entanto, diversos fatores do ambiente podem interferir na produção desta cultura. Dentre eles se destacam os relacionados à ocorrência das plantas daninhas.

No Estado de Goiás tem ocorrido com freqüência, nos canaviais, as plantas daninhas carrapicho-de-carneiro (Acanthospermum hispidum), apaga-fogo (Alternanthera tenella), corda-de-viola (Ipomoea grandifolia), dentre outras, as quais podem afetar, em determinadas situações, a produção da cana-de-açúcar.

Para o eficiente controle das plantas infestantes, os métodos físicos, mecânicos, culturais (coberturas mortas) e químicos (uso de herbicidas aplicados em pré-emergência e pós-emergência), têm sido utilizados na cana-de-açúcar (Victória Filho, 1993).

A utilização de herbicidas na cultura da cana-de-açúcar tem aumentado consideravelmente nos últimos anos e cada um destes produtos possue características intrínsecas e, se aplicados corretamente, produzirão resultados adequados no controle da flora daninha.

Atualmente, o custo do herbicida tem sido decisivo na escolha do mesmo, uma vez que o controle das plantas daninhas representa em média 30 a $38 \%$ do custo total da implantação do canavial e 40 a $45 \%$ do custo de tratamento da soqueira (Peixoto, 1991).

Herbicidas como 2,4-D, clomazone+ametryne e hexazinone/diuron, aplicados em pré-emergência, têm proporcionado eficiente controle de diversas espécies de plantas daninhas, conforme atestam Christoffoleti et al. (1995), Mascarenhas et al. (1995) e Velini et al. (1992).

Atualmente, como uma nova alternativa para o controle de plantas infestantes na cultura da cana-de-açúcar, o herbicida trifloxysulfuron-sodium em combinação com ametrine, aplicados em pós-emergência, tem proporcionado eficiente controle de várias espécies infestantes e são seletivos para a cana-de-açúcar (Soares et al., 2000).

Os objetivos deste trabalho foram avaliar a eficácia biológica dos herbicidas trifloxysulfuron-sodium com ametryne no controle das plantas daninhas, bem como avaliar a seletividade para a cultura da cana-de-açúcar.

\section{MATERIAL E MÉTODOS}

Foi instalado um ensaio em campo, na Usina Santa Helena, em Santa Helena de Goiás-GO, sendo plantada a variedade RB 84-5257, no espaçamento de 1,4 m, no dia 13/ 09/99. A pulverização foi efetuada em pós-emergência, no dia 12/11/99, com as plantas daninhas dicotiledôneas no estádio de 4 a 6 folhas e as gramíneas com 2 a 3 perfilhos.

No dia da aplicação dos tratamentos foi realizada a

Tabela 1. Herbicidas utilizados com as respectivas doses do produto comercial e do ingrediente ativo. Santa Helena de Goiás GO.1999/2000.

Herbicida Dose

\begin{tabular}{|c|c|c|c|}
\hline Produto Comercial (P.C.) & Ingrediente Ativo (I.A.) & $\begin{array}{c}\text { P.C. } \\
\text { (g ou } 1 / \text { ha) }\end{array}$ & $\begin{array}{l}\text { I.A. } \\
\text { (g/ha) }\end{array}$ \\
\hline A12001A (Krismat) ${ }^{1}$ & Trifloxysulfuron-sodium/ametryne (MF) ${ }^{2}$ & $1750 \mathrm{~g}$ & $32 / 1280$ \\
\hline A12001A (Krismat) ${ }^{1}$ & Trifloxysulfuron-sodium/ametryne (MF) ${ }^{2}$ & $2000 \mathrm{~g}$ & $37 / 1463$ \\
\hline A12001A (Krismat) ${ }^{1}$ & Trifloxysulfuron-sodium/ametryne (MF) ${ }^{2}$ & $2250 \mathrm{~g}$ & $42 / 1646$ \\
\hline CGA $362622+$ Gesapax $500^{1}$ & Trifloxysulfuron-sodium+ametryne (MT) ${ }^{3}$ & $50 \mathrm{~g}+31$ & $37 / 1500$ \\
\hline Velpar K & Hexazinone/diuron & $2500 \mathrm{~g}$ & $330 / 1170$ \\
\hline CGA $362622^{1}$ & Trifloxysulfuron-sodium & $30 \mathrm{~g}$ & 22 \\
\hline
\end{tabular}

${ }^{1}$ Foi adicionado à calda de pulverização o adjuvante Extravon a $0,2 \%$ v.v

${ }^{2} \mathrm{MF}=$ mistura formulada

${ }^{3} \mathrm{MT}=$ mistura em tanque 
contagem das plantas daninhas nas parcelas experimentais, obtendo-se para o carrapicho-de-carneiro (17 plantas $\left./ \mathrm{m}^{2}\right)$, erva-de-santa-luzia ( 15 plantas $/ \mathrm{m}^{2}$ ), capim-colchão (11 plantas $\left./ \mathrm{m}^{2}\right)$ e apaga-fogo ( 28 plantas $\left./ \mathrm{m}^{2}\right)$.

O delineamento experimental adotado foi o de blocos ao acaso, com oito tratamentos e quatro repetições. Os herbicidas testados encontram-se relacionados na Tabela 1. Além dos seis tratamentos com herbicidas foram utilizados ainda uma testemunha capinada e uma testemunha sem capina. As parcelas experimentais mediram $7 \mathrm{~m} \mathrm{x} 3 \mathrm{~m}=21 \mathrm{~m}^{2}$. $\mathrm{O}$ equipamento utilizado para a aplicação dos produtos foi um pulverizador costal, pressurizado a $\mathrm{CO}_{2}$, com pontas de pulverização (bicos) tipo leque, série TT 110.02 , calibrados para $3,0 \mathrm{~kg} / \mathrm{cm}^{2}$ de pressão, consumindo $200 \mathrm{l} / \mathrm{ha}$ de calda.

As condições climáticas registradas no momento da aplicação foram: $28^{\circ} \mathrm{C}$ de temperatura do ar, umidade relativa de $62 \%$ e com $30 \%$ de nebulosidade. As precipitações diárias registradas em Santa Helena de Goiás, no período de outubro/99 a janeiro de 2000, encontram-se discriminadas no Anexo 1.

Aos 15, 30 e 60 dias após a aplicação dos tratamentos (DAT), foram realizadas avaliações de toxicidade e eficácia biológica, adotando-se a escala percentual da European Weed Reseach Council (EWRC), na qual 0\% corresponde a ausência de intoxicação à cultura ou nenhum controle das plantas daninhas e $100 \%$ a dano total à cultura ou controle total das plantas daninhas.

$\mathrm{Na}$ colheita da cana-de-açúcar avaliou-se a altura de planta, número de colmos (perfilhos) e produção da cultura. Avaliou-se ainda, o índice de controle das plantas daninhas nas parcelas tratadas, levando-se em consideração o grau de infestação e o porte das plantas daninhas, adotando-se a escala arbitrária: excelente, bom, médio, difícil e impossível.
Os parâmetros altura de planta, número de colmos e produção da cultura foram submetidos à análise de variância e as médias comparadas pelo teste de Tukey a $5 \%$ de probabilidade.

\section{RESULTADOS E DISCUSSÃO}

Aos 15 dias após os tratamentos (DAT), carrapichode-carneiro, apaga-fogo, erva-de-santa-luzia e capim-colchão foram eficientemente controlados pela mistura formulada de trifloxysulfuron-sodium/ametryne (32/1280, 37/1463 e 41/ $1646 \mathrm{~g} / \mathrm{ha})$ e pela mistura em tanque de trifloxysulfuronsodium+ametryne $(37+1500 \mathrm{~g} / \mathrm{ha})$, equivalendo-se ao padrão hexazinone/diuron (330/1170 g/ha) (Tabela 2).

Os altos níveis de controle foram mantidos até 60 DAT. A partir deste período a cultura proporcionou o fechamento dos espaços entre fileiras, provocando o sombreamento do solo e evitando a reinfestação das parcelas tratadas com os herbicidas.

Soares et al. (2000), também conseguiram controle eficiente de capim-colchão e carrapicho-de-carneiro, com níveis superiores a $90 \%$, com o uso da mistura de trifloxysulfuron-sodium/ametryne, concordando com os resultados obtidos neste experimento.

Trifloxysulfuron-sodium a $22 \mathrm{~g} / \mathrm{ha}$, apesar de ter proporcionado controle inferior das espécies infestantes dicotiledôneas (carrapicho-de-carneiro, apaga-fogo e erva-desanta-luzia), mesmo assim os níveis de controle foram considerados eficientes, obtendo-se aos 60 DAT, índice mínimo de $85 \%$. Admitindo-se $80 \%$ o nível mínimo aceitável de controle, o trifloxysulfuron-sodium aplicado isolado pode ser utili-

Tabela 2. Resultados médios de controle de plantas daninhas, obtidos com herbicidas de pós-emergência na cultura da canade-açúcar aos 15, 3060 dias após os tratamentos (DAT). Santa Helena de Goiás-GO. 1999/2000.

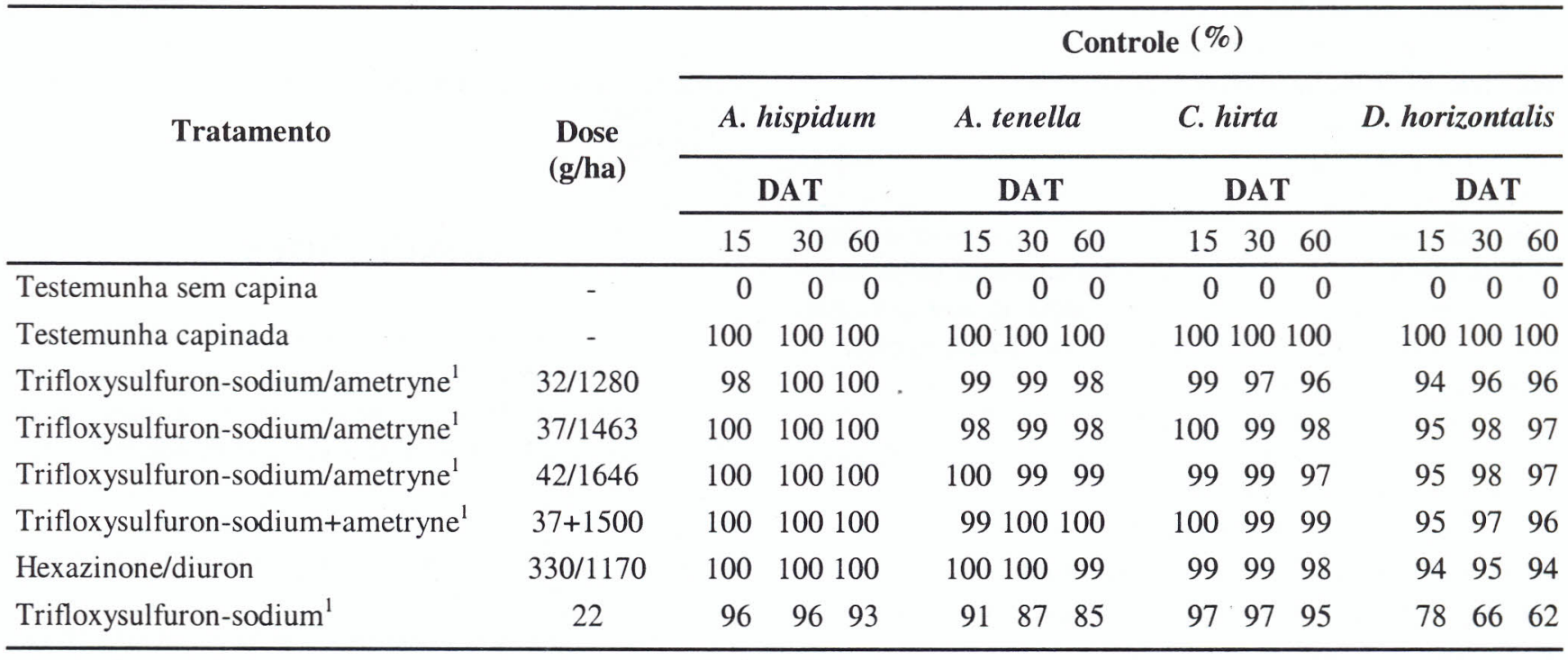

${ }^{1}$ Foi adicionado à calda de pulverização Extravon a $0,2 \%$ v/v 
Antônio Carlos de Barros e Denilson Miranda Leonel

Tabela 3. Resultados médios de toxicidade, índice de colheita, altura de plantas, $\mathrm{n}^{\circ}$ de perfilhos e produtividade da cana-deaçúcar. Santa Helena de Goiás-GO. 1999/2000.

\begin{tabular}{|c|c|c|c|c|c|c|c|c|c|}
\hline \multirow{2}{*}{ Tratamento } & \multirow{2}{*}{$\begin{array}{l}\text { Dose } \\
\text { (g/ha) }\end{array}$} & \multicolumn{3}{|c|}{$\begin{array}{l}\text { Toxicidade } \\
\text { DAT }\end{array}$} & \multirow{2}{*}{$\begin{array}{c}\text { Índice de } \\
\text { controle } \\
\text { na } \\
\text { colheita }^{2}\end{array}$} & \multirow{2}{*}{$\begin{array}{c}\text { Altura das } \\
\text { plantas da } \\
\text { cultura } \\
(\mathrm{cm})\end{array}$} & \multirow{2}{*}{$\begin{array}{l}\text { Perfilho } \\
\quad\left(\mathbf{n}^{\circ}\right)\end{array}$} & \multicolumn{2}{|c|}{ Produtividade } \\
\hline & & 15 & 30 & 60 & & & & $(\mathrm{t} / \mathrm{ha})$ & $\%$ \\
\hline Testemunha sem capina & - & 0 & 0 & 0 & Médio & $272,7 \mathrm{a}^{3}$ & $21 \mathrm{a}$ & $117,5 \mathrm{a}$ & 94,6 \\
\hline Testemunha capinada & - & 0 & 0 & 0 & Excelente & $269,5 \mathrm{a}$ & $23 a$ & 124,2 a & 100,0 \\
\hline $\begin{array}{l}\text { Trifloxysulfuron-sodium/ } \\
\text { ametryne }^{1}\end{array}$ & $\begin{array}{l}32 / \\
1280\end{array}$ & 4 & 0 & 0 & Excelente & $263,0 \mathrm{a}$ & $21 \mathrm{a}$ & $127,8 \mathrm{a}$ & 102,8 \\
\hline $\begin{array}{l}\text { Trifloxysulfuron-sodium/ } \\
\text { ametryne }^{1}\end{array}$ & $\begin{array}{c}37 / \\
1463\end{array}$ & 5 & 0 & 0 & Excelente & 265,5 a & $22 \mathrm{a}$ & 129,8 a & 104,5 \\
\hline $\begin{array}{l}\text { Trifloxysulfuron-sodium/ } \\
\text { ametryne }^{1}\end{array}$ & $\begin{array}{c}42 / \\
1646\end{array}$ & 5 & 0 & 0 & Excelente & 257,2 a & $23 \mathrm{a}$ & 120,6 a & 97,1 \\
\hline $\begin{array}{l}\text { Trifloxusulfuron-sodium/ } \\
\text { ametryne }^{1}\end{array}$ & $\begin{array}{c}37+ \\
1500\end{array}$ & 5 & 0 & 0 & Excelente & 268,0 a & $23 \mathrm{a}$ & $127,8 \mathrm{a}$ & 102,8 \\
\hline $\begin{array}{l}\text { Hexazinone/ } \\
\text { diuron }\end{array}$ & $\begin{array}{l}330 / \\
1170\end{array}$ & 5 & 0 & 0 & Excelente & $263,7 \mathrm{a}$ & $22 \mathrm{a}$ & $128,7 \mathrm{a}$ & 103,6 \\
\hline Trifloxysulfuron-sodium ${ }^{1}$ & $22 \mathrm{~g}$ & 3 & 0 & 0 & Bom & 262,5 a & $22 \mathrm{a}$ & $118,1 \mathrm{a}$ & 95,0 \\
\hline C.V. $(\%)$ & - & - & - & - & - & 4,6 & 8,7 & 8,0 & \\
\hline
\end{tabular}

${ }^{1}$ Adicionado o adjuvante Extravon a $0,2 \%$ v/v

${ }^{2}$ Escala utilizada: excelente, bom, médio, difícil e impossível.

${ }^{3}$ Médias na coluna, seguidas das mesmas letras, não diferem significativamente entre si, pelo teste de Tukey a 5\% de probabilidade.

zado na cultura da cana-de-açúcar, para controle de plantas daninhas de folha larga. Entretanto, foi baixo o controle do capim-colchão, considerando a infestação da área (Tabela 2).

Os níveis de controle das plantas daninhas, proporcionados pela mistura formulada de trifloxysulfuron-sodium/ ametryne foram semelhantes ao controle obtido por trifloxysulfuron-sodium+ametrine, em mistura em tanque.

De modo geral, o controle das plantas daninhas deve ser efetuado até 40 dias após a emergência da cana-de-açúcar e se estender até no mínimo 150 dias (Kuva et al., 1997), para que não haja interferência negativa na produção da cultura. Isto foi conseguido neste experimento, com a aplicação dos herbicidas, ficando evidenciado ao avaliar-se o índice de controle das plantas daninhas na colheita da cana-de-açúcar. Este índice foi considerado excelente nos tratamentos químicos, exceto para trifloxysulfuron-sodium aplicado isoladamente, que proporcionou índice bom (Tabela 3), enquanto que, para as testemunhas com e sem capina, foram respectivamente excelente e médio.

A altura de plantas e o número de perfilhos na colheita da cana-de-açúcar não foram influenciados significativamente pela aplicação dos tratamentos (Tabela 3).

Quanto à produtividade da cana-de-açúcar, também não foram observadas diferenças significativas entre os tratamentos utilizados (Tabela 3 ), embora a produtividade relativa obtida na testemunha sem capina tenha sido $5,4 \%$ menor do que aquela conseguida na testemunha capinada.
A densidade populacional do complexo de plantas daninhas presente no experimento foi relativamente baixa, não causando prejuízos significativos à produtividade da canade-açúcar, apesar de ter proporcionado a menor produtividade na testemunha sem capina.

A aplicação dos herbicidas provocou intoxicação leve à cultura da cana-de-açúcar, pouco perceptível na fase inicial, ocorrendo rápida recuperação da cultura (Tabela 3). Na segunda avaliação (30 DAT), no entanto, a cultura da canade-açúcar apresentava-se recuperada, revelando que os herbicidas testados foram seletivos para a cana-de-açúcar cv. RB 84-5257.

\section{CONCLUSÕES}

Carrapicho-de-carneiro, apaga-fogo, erva-de-santaluzia e capim-colchão foram eficientemente controlados pela mistura formulada de trifloxysulfuron-sodium/ametryne (32/ 1280, 37/1463 e 42/1646 g/ha + espalhante adesivo a 0,2\% v.v) e pela mistura em tanque de trifloxysulfuronsodium+ametryne $(37+1500 \mathrm{~g} / \mathrm{ha}+$ espalhante a $0,2 \% \mathrm{v} . \mathrm{v})$, obtendo-se níveis de controle equivalentes à hexazinone/ diuron $(330 / 1170 \mathrm{~g} / \mathrm{ha})$.

Trifloxysulfuron-sodium (22 g/ha) + espalhante adesivo $(0,2 \% \mathrm{v} / \mathrm{v})$ proporcionou eficiente controle das plantas 
daninhas de folhas largas e baixo controle de capim-colchão.

Nas doses testadas, os produtos foram seletivos para a cultura da cana-de-açúcar.

\section{AGRADECIMENTOS}

Os autores expressam agradecimentos ao técnico agrícola Euvagner Garcia Chagas e ao operário rural Vilmar Rodrigues Nascimento, pela valiosa colaboração na instalação e condução do experimento.

\section{LITERATURA CITADA}

CHRISTOFFOLETI, P. J.; CAMPO, J. A. D.; ORSI JR, F. Controle de plantas daninhas em condições de pósemergência inicial na cultura da cana-de-açúcar (Saccharum spp.) através dos herbicidas clomazone + ametrina. In: CONGRESSO BRASILEIRO DA CIÊNCIA DAS PLANTAS DANINHAS, 20. Florianópolis, 1995. Resumos... Florianópolis, SC: SBCPD, 1995. p. 202-204.

KUVA, M. A.; PITELLI, R. A.; GIMENES, J. D.; BORGES, L. A. Efeitos de períodos de convivência e de controle das plantas daninhas na cultura da cana-de-açúcar (Saccharum spp.), em comunidade infestante com predomínio de capim-braquiária (Brachiaria decumbens) e capim-colonião (Panicum maximum). In: CONGRESSO BRASILEIRO DA CIÊNCIA DAS PLANTAS DANINHAS, 21. Caxambú, 1997. Resumos...Viçosa, MG: SBCPD, 1997. p. 263.

MASCARENHAS, M. H. T.; GALLI, A. J. B.; VIANA, M. C. M.; MACÊDO, B. A. R.; LARA, J. F. R. Eficiência do halosulfuron no controle de tiririca (Cyperus rotundus) na cultura da cana-de-açúcar. Planta Daninha, v.13, n.2, p.60-80, 1995.

PEIXOTO, A. B. Tratos culturais e químicos. STAB, Piracicaba, v.9, n.3, p.18-21, 1991.

SOARES, J. E.; NEMOTO, L.; HUDETZ, M. Tryfloxisulfuron-sodium (CGA 362 622) novo herbicida seletivo para a cultura de cana-de-açúcar. In: CONGRESSO BRASILEIRO DA CIÊNCIA DAS PLANTAS DANINHAS, 22. Foz do Iguaçú, 2000. Resumos...Londrina, PR: SBCPD, 2000. p.318.
VELINI, E. D.; FREDERICO, L. A. M.; MORELLI, J. L.; MARUBAUYASHI, O. M. Avaliação dos efeitos de doses do herbicida clomazone, aplicado em pós-emergência inicial, sobre o crescimento e produtividade de soqueira de cana-de-açúcar (Saccharum officinarum $\mathrm{cv}$. SP 71-1406). STAB, Piracicaba, v.10, n.4, p.13-16, 1992.

VICTÓRIA FILHO, R. Controle de plantas daninhas na cultura da cana-de-açúcar. In: CÂMARA, G. M. S.; OLIVEIRA, E. A. M., eds. Produção de cana-de-açúcar. Piracicaba: Fundação de Estudos Agrários "Luiz de Queiróz", 1993. p.174-183.

Anexo 1. Precipitações pluviais diárias registradas ( $\mathrm{mm})$ no período de outubro de 1999 a janeiro de 2000 . Santa Helena de Goiás-GO. 1999/2000.

\begin{tabular}{|c|c|c|c|c|}
\hline \multirow[t]{2}{*}{ DIA } & \multicolumn{3}{|c|}{1999} & \multirow{2}{*}{$\frac{2000}{\text { JAN. }}$} \\
\hline & OUT. & NOV. & DEZ. & \\
\hline 1 & 0,0 & 0,0 & 0,0 & 0,0 \\
\hline 2 & 0,0 & 0,0 & 0,0 & 28,8 \\
\hline 3 & 0,0 & 0,0 & 18,6 & 83 \\
\hline 4 & 0,0 & 45,0 & 0,0 & 65,6 \\
\hline 5 & 0,0 & 7,4 & 0,1 & 0,0 \\
\hline 6 & 3,1 & 0,0 & 0,3 & 5,4 \\
\hline 7 & 0,0 & 0,0 & 0,0 & 3,1 \\
\hline 8 & 1,4 & 0,0 & 14,9 & 1,5 \\
\hline 9 & 0,0 & 0,4 & 12,9 & 0,0 \\
\hline 10 & 0,0 & 1,2 & 64,3 & 0,0 \\
\hline 11 & 0,0 & 0,0 & 1,4 & 0,0 \\
\hline 12 & 0,0 & 0,0 & 23,1 & 0,0 \\
\hline 13 & 0,0 & 32,5 & 0,5 & 4,8 \\
\hline 14 & 11,8 & 15,3 & 0,0 & 0,0 \\
\hline 15 & 0,0 & 0,0 & 3,4 & 0,0 \\
\hline 16 & 0,0 & 0,0 & 0,0 & 0,0 \\
\hline 17 & 0,0 & 0,0 & 0,0 & 0,0 \\
\hline 18 & 1,6 & 0,0 & 0,0 & 0,4 \\
\hline 19 & 3,0 & 0,0 & 0,0 & 0,0 \\
\hline 20 & 0,0 & 0,0 & 0,0 & 4,2 \\
\hline 21 & 0,0 & 41,9 & 0,0 & 26 \\
\hline 22 & 0,0 & 0,0 & 1,1 & 0,2 \\
\hline 23 & 0,0 & 6,4 & 0,0 & 1,6 \\
\hline 24 & 0,0 & 3,2 & 1,1 & 0,0 \\
\hline 25 & 4,1 & 3,2 & 0,0 & 4,2 \\
\hline 26 & 0,0 & 8,8 & 13,0 & 22 \\
\hline 27 & 47,2 & 16,7 & 0,0 & 21 \\
\hline 28 & 1,3 & 1,2 & 35,4 & 1,6 \\
\hline 29 & 0,0 & 0,0 & 0,0 & 1,7 \\
\hline 30 & 0,4 & 0,0 & 8,4 & 0,0 \\
\hline 31 & 0,0 & 0,0 & 31,6 & 0,9 \\
\hline Total & 101,8 & 183,5 & 229,7 & 283,5 \\
\hline
\end{tabular}


